\title{
Dynamic Electropulsing Induced Evolution of Basal Texture and Its Effect on Properties of Magnesium Alloy AZ61
}

\author{
Guoliang $\mathrm{Hu}^{1,2}$, Zhenting Wang ${ }^{2}$, Yaohua Zhu ${ }^{3}$, Jianan Liu ${ }^{1}$ and Guoyi Tang ${ }^{1}$ \\ ${ }^{1}$ Advanced Materials Institute, Graduate School at Shenzhen, Tsinghua University, P. R. China \\ ${ }^{2}$ Department of Materials Science, HeiLongJiang Institute of Science and Technology, P. R. China \\ ${ }^{3}$ Department of Industrial and Systems Engineering, Hong Kong Polytechnic University, Hong Kong, P. R. China
}

\begin{abstract}
The dynamic electropulsing induced basal-texture evolution in an AZ61 magnesium alloy was studied by scanning electron microscopy, and backscattered electron microscopy techniques. It was found that electropulsing reduced residual stress inside the rolled magnesium alloy AZ61, which resulted in decreases of both twins and non-basal slips. Electropulsing improved mechanical properties of the alloy. The mechanism of the electropulsing induced texture evolution is discussed from the point of view of electropulsing dynamics. [doi:10.2320/matertrans.M2011092]
\end{abstract}

(Received March 29, 2011; Accepted May 30, 2011; Published July 25, 2011)

Keywords: compressive stress, basal texture, electro-rolling, twin, microstructure

\section{Introduction}

It is well known that a magnesium alloy sheet exhibits poor formability in conventional forming operation at ambient temperature, because of its hexagonal close packed (hcp) structure with limited slipping systems at room temperature. ${ }^{1-3)}$ Repeated annealing, i.e. recrystallization, is therefore required after cold deformation in order to reduce residual stresses inside the alloy sheet being worked. A newly developed process, electropulsing treatment (EPT) was recognized for its high efficiency in reducing residual stresses in alloys. As an alternative to traditional thermal and mechanical processes, EPT has attracted great attention. Extensive studies have been carried out in materials science and engineering, such as electroplasticity, ${ }^{4,5)}$ electromigration, ${ }^{6)}$ and defect structure. ${ }^{7)}$

In our previous studies, it was found that EPT enhanced the recrystallization rate of $\mathrm{Fe}-3 \% \mathrm{Si}$ alloy. ${ }^{8,9)}$ However, little has been studied on the effects of electropulsing on microstructure and plastic behavior of magnesium alloys. The present work deals with electropulsing induced micro-texture evolution and its effect on the plastic elongation of the alloy AZ61.

\section{Experimental Procedures}

AZ61 magnesium alloy samples (Al-6 mass\%, Zn1 mass $\%$ ) were extruded to form strips $3 \mathrm{~mm}$ wide and $1.5 \mathrm{~mm}$ thick. The as-received strips were rolled in one pass down to $1.30 \mathrm{~mm}$ under electropulsing (EPR), and correspondingly the compressive deformation rates reached $13.3 \%$. The rolling direction (RD) was parallel to the extrusion one. Subsequently, tensile testing was carried out on the as-rolled samples.

The AZ61 strip moved at a speed of $2 \mathrm{~m} / \mathrm{min}$ through a distance of $225 \mathrm{~mm}$ between two electrodes. It took about $7 \mathrm{~s}$ to move the strip from the anode to cathode. A custom made electropulsing generator was utilized to discharge multiple positive pulses. The pressure in the anode was just sufficient to keep good electrical contact, and in the cathode a larger pressure was implemented for rolling. Under the cathode blow roller a stress sensor was designed to monitor compressive stress. Pre-compressive stress was $8500 \mathrm{~Pa}$. The parameters of frequency of electropulsing were monitored by a Hall Effect sensor connected to an oscilloscope, and the temperature of the AZ61 strip near the cathode was measured using a Raytek MX2 infrared thermoscope. Both the frequency of electropulsing and the temperature are listed in Table 1. Prior to optical examination, the samples were polished with 2.5 and $0.5 \mu \mathrm{m}$ diamond paste, and etched in acetic picral $(5 \mathrm{ml}$ acetic acid, $6 \mathrm{~g}$ picric acid, $35 \mathrm{ml}$ ethanol, and $5 \mathrm{ml}$ water) for $3 \mathrm{~s}$. X-ray texture analysis was conducted on the surface of the cold-rolled and EPR AZ61 samples by $\mathrm{X}$-ray diffraction in the back reflection mode with $\mathrm{Cu}-K_{\alpha}$ radiation.

In order to clarify the effect of the electropulsing on the changes of intensity of the basal texture, various thermal rolling (THR) were carried out in parallel with the EPR processes.

\section{Results}

The optical micrographs of the cold-rolled and electropusling-rolled (EPR) specimens are shown in Fig. 1. A large number of shear bands and twins resulting from the intensified stress were observed in the as cold-rolled specimen, as shown in Fig. 1(a). After $80 \mathrm{~Hz} / 56^{\circ} \mathrm{C}$ for about $7 \mathrm{~s}$, twinning decreased (Fig. 1(b)). With the increase of the frequency to $110 \mathrm{~Hz} / 75^{\circ} \mathrm{C}$ for about $7 \mathrm{~s}$, the twinning further decreased (Fig. 1(c)) After EPR with a frequency of $150 \mathrm{~Hz}$ / $97^{\circ} \mathrm{C}$ for about $7 \mathrm{~s}$, the twinning was considerably decreased, as shown in Fig. 1(d).

The basal texture (0002) pole figures of both THR- and EPR-AZ61 alloy specimens were examined using XRD technique, as shown in Fig. 2(a) and (b), respectively.

The corresponding (0002) pole figure (Fig. 2(a)) was of a random basal plane orientation with a max intensity of 9.8 . With increasing frequency of electropulsing, the $\max$ 
Table 1 The parameters of both EPR and cold rolling.

\begin{tabular}{|c|c|c|c|c|c|}
\hline $\begin{array}{l}\text { Sample } \\
\text { No }\end{array}$ & $\begin{array}{l}\text { Frequency } \\
\quad(\mathrm{Hz})\end{array}$ & $\begin{array}{c}\text { Voltage } \\
\text { (V) }\end{array}$ & $\begin{array}{c}\text { Pre-compressive } \\
\text { stress } \\
(\mathrm{Pa})\end{array}$ & $\begin{array}{l}\text { Compressive stress } \\
\text { during rolling } \\
(\mathrm{Pa})\end{array}$ & $\begin{array}{c}\text { Temperature } \\
\left({ }^{\circ} \mathrm{C}\right)\end{array}$ \\
\hline Cold rolling & 0 & 0 & 8500 & $8850 \sim 9000$ & 0 \\
\hline EPR1 & 80 & 72 & 8500 & $8300 \sim 8350$ & 56 \\
\hline EPR2 & 110 & 72 & 8500 & $8150 \sim 8200$ & 75 \\
\hline EPR3 & 150 & 72 & 8500 & $8000 \sim 8100$ & 97 \\
\hline
\end{tabular}
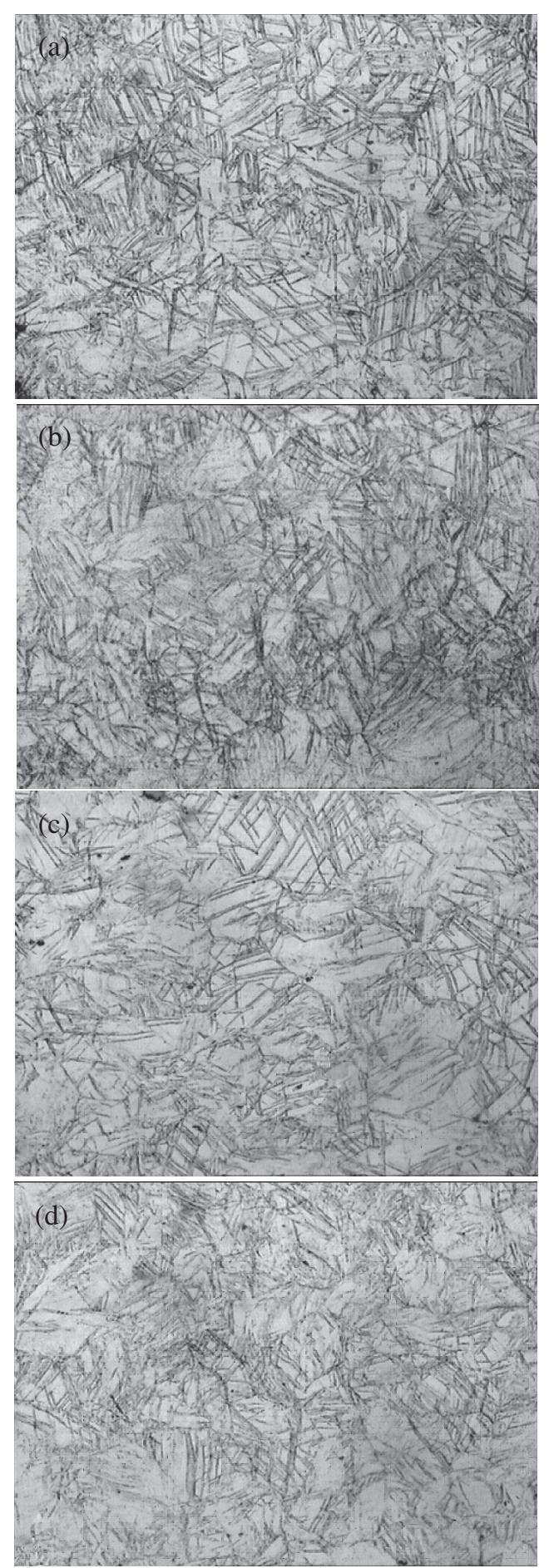

Fig. 1 Optical microstructure of the cool rolled and EPR specimens: (a) after cold rolling, (b) after EPR at $80 \mathrm{~Hz}$ for about $7 \mathrm{~s}$, (c) after EPR at $110 \mathrm{~Hz}$ for about $7 \mathrm{~s}$ and (d) after EPR at $150 \mathrm{~Hz}$ for about $7 \mathrm{~s}$.
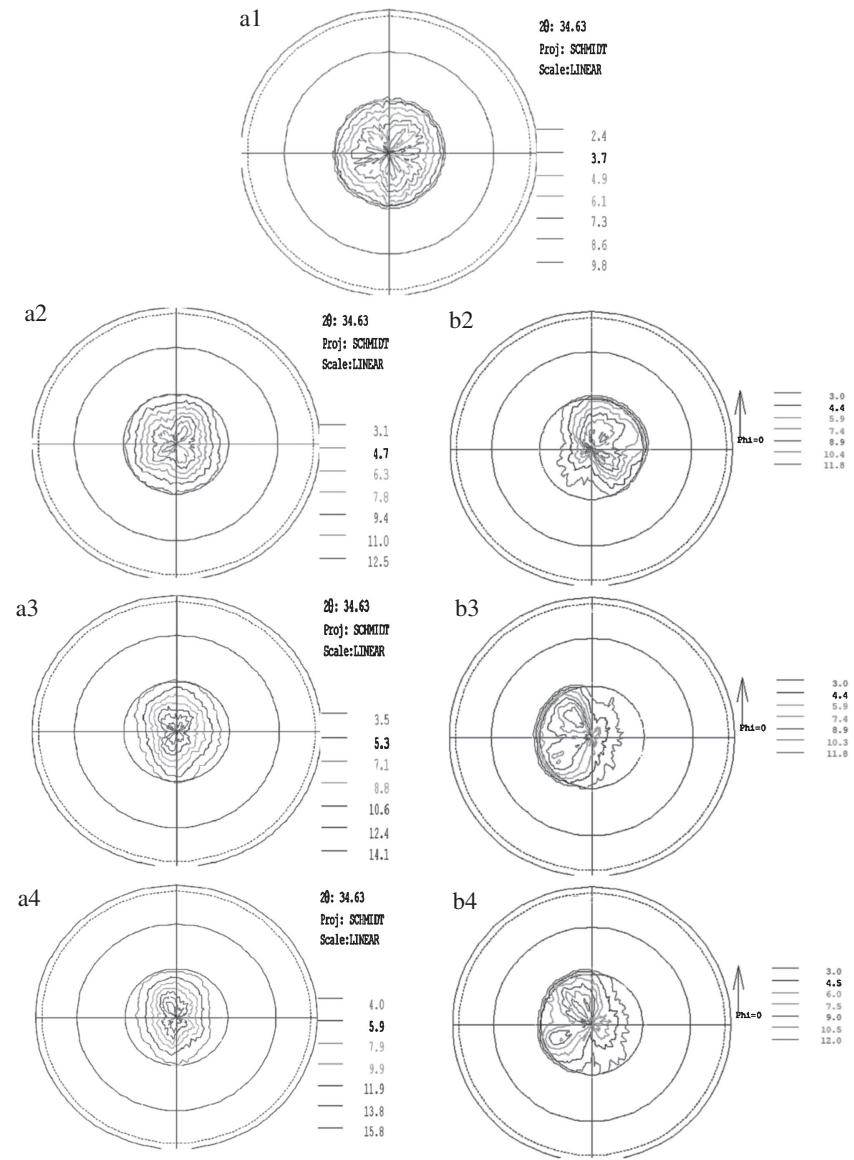

Fig. 2 (0002) pole figures of cool rolled-(b) specimen and both EPR-(a) and THR-(b) specimens: (a1) after cold rolling, (a2) after EPR at $80 \mathrm{~Hz}$ $\left(56^{\circ} \mathrm{C}\right),(\mathrm{a} 3)$ after EPR at $110 \mathrm{~Hz}\left(75^{\circ} \mathrm{C}\right),(\mathrm{a} 4)$ after EPR at $150 \mathrm{~Hz}\left(97^{\circ} \mathrm{C}\right)$; (b2) $56^{\circ} \mathrm{C} \mathrm{THR,} \mathrm{(b3)} 75^{\circ} \mathrm{C} \mathrm{THR,} \mathrm{(b4)} 97^{\circ} \mathrm{C} \mathrm{THR}$.

intensity of basal texture increased to $12.5\left(80 \mathrm{~Hz} / 56^{\circ} \mathrm{C}\right)$ and the max intensity of basal texture $\left(110 \mathrm{~Hz} / 75^{\circ} \mathrm{C}\right)$ reached 14.7, as shown in Fig. 2(a2) and (a3).

Accordingly, the pole figure of the (0002) basal plane indicated became relatively concentrated, and the dispersion of the tilt basal plane became reduced, as shown in Fig. 2(a4). Simultaneously, due to the basal tilt from normal direction to rolling direction, a double peak of basal plane texture appeared with the $\max$ intensity of 15.8. The compressive stress decreased with increasing of frequency of the electropulsing, as indicated in Table 1.

The relationship between basal texture intensity and temperature of the EPR specimens are shown as a curve (a) in Fig. 3. It can be seen that the (0002) basal texture increased when the frequency of electropulsing increased. 


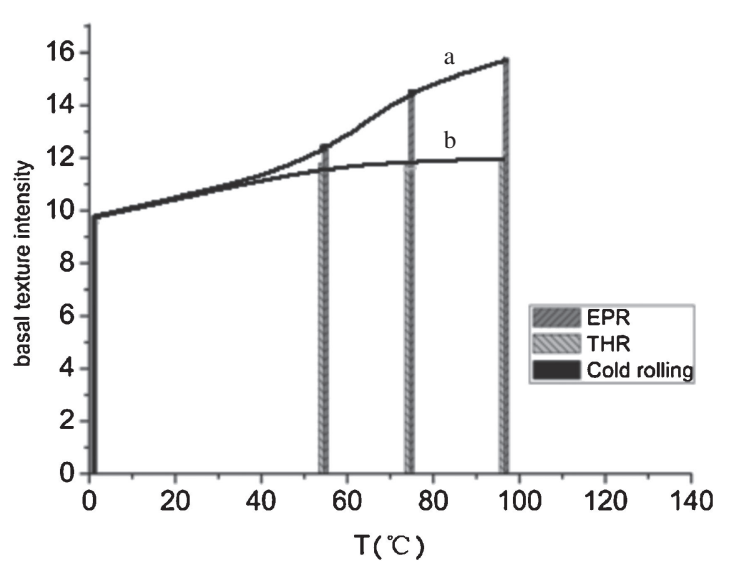

Fig. 3 The relationship between basal texture intensity and temperature of EPR and THR AZ61 alloy specimens, curve (a) for EPR and curve (b) for THR.

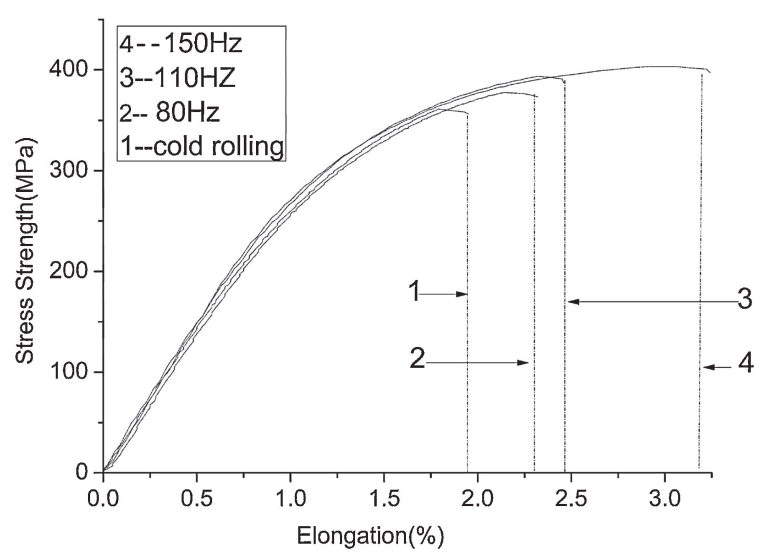

Fig. 4 Variations in stress strength and elongation under both cold rolled and EPR.

In comparison with the electropulsing induced texture evolution, the THR was performed at various surface temperatures of the specimens: $56^{\circ} \mathrm{C}, 75^{\circ} \mathrm{C}$ and $97^{\circ} \mathrm{C}$, respectively. The (0002) pole figures of the basal texture are shown in Fig. 2(b). No apparent changes of the (0002) texture were observed at $56^{\circ} \mathrm{C}, 75^{\circ} \mathrm{C}$ and $97^{\circ} \mathrm{C}$ in the THR specimens.

Accordingly, the relationship between the intensity of the (0002) basal texture and the THR temperature is shown as a curve (b) in Fig. 3. Compared with that in the cold rolled specimen, only a small amount of increase in the intensities of the basal texture was detected in the THR specimens, due to the decreasing of residual stress. The intensities of the (0002) basal texture remained stable in the THR specimens.

The relationship between the frequency of electropulsing and the mechanical properties of the AZ61 alloy specimens are shown in Fig. 4. The max elongations of the cold rolled specimen and the EPR specimens with various frequencies of $80 \mathrm{~Hz} / 56^{\circ} \mathrm{C}, 110 \mathrm{~Hz} / 75^{\circ} \mathrm{C}$, and $150 \mathrm{~Hz} / 97^{\circ} \mathrm{C}$ are indicated by arrows 1, 2, 3 and 4 in Fig. 4, respectively. It can be seen that the EPR greatly affected mechanical properties. Under cold rolling, the tensile stress strength was $340 \mathrm{MPa}$, with only an elongation of $1.9 \%$. While under EPR, both strength and elongation were improved with increasing frequency of electropulsing. Under EPR at $150 \mathrm{~Hz} / 97^{\circ} \mathrm{C}$, the strength reached $400 \mathrm{MPa}$ with a higher elongation of $3.2 \%$.

\section{Discussion}

In magnesium alloys AZ61, there are the basal $\langle a\rangle$ slip systems and non-basal systems including prismatic $\langle a\rangle$ slip and pyramidal $\langle c+a\rangle$ slip systems. The critical resolved shear stress (CRSS) varied according to the texture of the samples being tested.

The CRSS for the non-basal systems is much larger than that for basal slip. ${ }^{10)}$ According to previous study, ${ }^{11)}$ in the extruded AZ61, grains with prismatic $\{10 \overline{1} 0\}$ and $\{11 \overline{2} 0\}$ and basal $\{0002\}$ planes parallel to the sheet plane were responsible for twinning. During cold rolling compressive stress reached almost to $9 \mathrm{KPa}$, whilst the interior shear stress tremendously increased and CRSS of non-basal slips became dominant. Therefore, more twins were produced and plenty of non-basal slips were activated. As a result, the basal splitting considerably enhanced ${ }^{12,13)}$ and the basal texture orientation became more random. Accordingly, the basal texture intensity under cold rolling is weak, only 9.8 .

As shown in Fig. 2(a) and Fig. 3, the basal texture intensities of the cold rolled specimen and the EPR specimens with $80 \mathrm{~Hz}, 110 \mathrm{~Hz}$ and $150 \mathrm{~Hz}$, were 9.8, 12.5, 14.7 and 15.8, respectively. With an increasing of frequency of the electropulsing the basal texture intensity became stronger. Thus, the effect of electropulsing on texture evolution was obvious in the AZ61 alloy.

Previous studies indicated that under electropulsing electron wind formed by the knock-on collision of high-rate electrons with atomic nuclei was beneficial to the mobility of dislocation. ${ }^{14,15)}$ Under the impact of transient stress, motivated dislocations were moving very quickly, even at ultrasonic speeds. ${ }^{16)}$

Electropulsing greatly accelerated movement of sliding dislocation, which resulted in fast annihilation of dislocation at grain boundaries and defects. ${ }^{17)}$ In accordance, interior stress caused by rolling reduced. In particular, activation of vacancies accelerated dislocation climbing ${ }^{18)}$ and further resulted in decrease of stress.

Under the EPR, the deformation resistance decreased, according to the formula: ${ }^{19)}$

$$
\sigma_{\mathrm{e}}=C[\varepsilon-(\varepsilon-\varepsilon)]^{m}=c\left\{2 \varepsilon-\varepsilon \ln \left(\frac{\sigma^{*}}{\sigma^{*}+\xi J}\right)+\frac{m^{*} \xi J}{\sigma^{*}}\right\}^{m}
$$

where $\sigma_{\mathrm{e}}$ is plastic stress under electropulsing, $C$ is constant, $\varepsilon$ is plastic strain caused by non-electropulsing, $\varepsilon_{\mathrm{e}}$ is plastic strain caused by electropulsing, $\sigma^{*}$ is the effective stress, $\xi$ is constant, $J$ is current density, $m^{*}=b \sigma^{*} A / k T$ (where $b$ is Burgers vector, $A$ is the area swept out per successful thermal fluctuation, and $k$ and $T$ are constant). With the increasing frequency $J$ becomes larger, according to the results of the experimental test: $J \propto \sqrt{\frac{f}{2}}$, where $f$ is the electropulsing frequency. The $f$ increased, but the $\sigma_{\mathrm{e}}$ decreased. Therefore, during EPR the compressive stress decreased with an increase in the frequency of electropulsing. In turn, the decrease of compressive stress was not favored by non-basal slipping and twinning. Thus, it can be seen that with increasing the frequency of electropulsing the twins considerably decreased. Meanwhile, the preferred basal texture orientation transformed from random to relatively concentrate, as shown in Fig. 2(a). 
Normally, a random basal texture favors enhancing the elongation of magnesium alloys and develops ductility, but the Fig. 4 showed the opposite. Under cold rolling with large reduction in one pass, deformation became inhomogeneous. Accordingly, the deformation capacity of basal slip, prismatic slip and twinning was readily exhausted. ${ }^{20)}$ As a result, strain hardening occurred. Under cold rolling the elongation of the AZ61 alloy decreased due to the strain hardening. While under electropulsing the annihilation of dislocation reduced the residual stresses caused during rolling, and the elongation was improved, as shown in Fig. 4.

\section{Conclusions}

In summary, it is concluded that under EPR, the compressive stress considerably decreased due to a great acceleration of both dislocation sliding and activation of vacancies, resulting in annihilation of dislocation. Compared with cold rolling, the EPR favored of transformation of the basal orientation from random to relatively concentrate because of reduction of the compressive stress. EPR reduced the residual stress, and elongation of the AZ61 alloy was improved.

\section{Acknowledgements}

This work was supported by the Young Teachers Fund of Heilongjiang Institute of Science and Technology (No. 4050) China and the Ph.D Fund of Nanshan District Shenzhen, P. R. China.

\section{REFERENCES}

1) M. M. Avedesian and H. Baker (Eds.): Magnesium and Magnesium Alloys, ASM Speciality Handbook, (ASM International, Metals Park, OH, 1999).

2) M. T. Perez-Prado and O. A. Ruano: Scr. Mater. 46 (2002) 149-155.

3) Q. Jin, S. Y. Shim and S. G. Lim: Scr. Mater. 55 (2006) 843-846.

4) H. Conrad, J. White, W. D. Cao, X. P. Lu and A. F. Sprecher: Mater. Sci. Eng. A 145 (1991) 1-12.

5) D. Yang and H. Conrade: Intermetallics 9 (2001) 943-947.

6) J. R. Lloyd and J. J. Clement: Appl. Phys. 32 (1996) 109-112.

7) V. E. Gromov, Y. F. Ivanov, E. V. Kozlov, E. Y. Suchkova, S. V. Konovaloc and V. A. Rybyanets: Proc. Electromagnetic fields effect on the structure and characteristics of materials, Ed. by Y. V. Baranov, V. E. Gromov and G. Y. Tang, (Novokuznetsk, Russia, 2009) pp. 209224.

8) G. L. Hu, C. H. Shek, Y. H. Zhu, G. Y. Tang and Q. Xu: Mater. Trans. 51 (2010) 1390-1394.

9) G. Hu, Y. H. Zhu, C. H. Shek and G. Y. Tang: J. Mater. Res. 26 (2011) in press.

10) R. Gehrmann, M. Frommert and G. Gottstein: Mater. Sci. Eng. A 395 (2005) 338-349.

11) M. T. Perez-Prado and O. A. Ruano: Scr. Mater. 48 (2003) 59-64.

12) R. A. Lebenson and C. N. Tome: Acta Metall. 41 (1993) 2611-2624.

13) A. Styczynski, C. H. Hartig, J. Bohlen and D. Letzig: Scr. Mater. 50 (2004) 943-947.

14) A. F. Sprecher, S. L. Mamnna and H. Conrad: Acta Metall. 34 (1986) 1145-1162.

15) H. Conrad and A. F. Sprecher: The Electroplastic Effect in Metals, Dislocation in Solids, Vol. 8, ed. by F. R. N. Nabarro (Elsevier, Amsterdam, 1989) p. 497.

16) H. J. Gao and P. Gumbsch: Science 283 (1999) 965-968.

17) Y. H. Zhu, S. To, W. B. Lee and X. M. Liu: Mater. Sci. Eng. A 501 (2009) 125-132.

18) Z. H. Xu, G. Y. Tang, S. Q. Tian and J. H. He: Mater. Sci. Eng. A 424 (2006) 300-306.

19) D. L. Li and E. L. Yu: Mater. Sci. Eng. A 505 (2009) 62-64.

20) R. Gehrmann, M. M. Frommert and G. Gottstein: Mater. Sci. Eng. A 395 (2005) 338-349. 